\title{
Barriers to Medication Adherence Among Women Living in Rural Areas Suffering from Hypertension: The Case of Dikgale-Communities
}

\author{
M. L. Shirindi ${ }^{1}$, J. C. Makhubele ${ }^{2}$ and J. Fraeyman ${ }^{3}$ \\ ${ }^{1}$ Social Work Department, College of Human Sciences, University of South Africa, \\ P.O. Box 392, UNISA, 0003, South Africa \\ ${ }^{2}$ School of Social Science, University of Limpopo, Private Bag X 1106, SOVENGA, \\ 0722, South Africa \\ ${ }^{3}$ Research Group Medical Sociology and Health Policy, University of Antwerp, Belgium \\ ${ }^{1}$ Telephone: +27 (0)12 429 6060, ${ }^{1}$ Facsimile: +27 (0) 124296744 \\ ${ }^{1}$ E-mail: shiriml@unisa.ac.za, Jabulani.Makhubele@ul.ac.za
}

KEYWORDS Intervention. Non-adherence. Chronic Disease. Empowerment. Under-resourced Areas

ABSTRACT Poor adherence to antihypertensive medications remains a significant challenge in the management of hypertension among women living in rural areas. The objective of the study was to assess the reasons of nonadherence in women suffering from hypertension. The researchers used a qualitative exploratory research design to conduct the study. A purposive sampling technique was used to select fifty (50) Black African women who participated in five (5) focus group interviews. The NVivo program was used to manage and organize the qualitative data. The study revealed that inadequate health literacy, financial constraints, forgetfulness and cultural differences are some of the barriers that prevent women from adhering to antihypertensive medication. Health promotion activities to empower women to become more proactive about their health needs and care should not be underestimated. As a result, they will be more likely to comply with their treatment, which will make them healthier in the long run.

\section{INTRODUCTION}

Medication adherence is generally defined as the extent to which a patient takes medication as prescribed by the medical practitioner (Sachdeva 2005). According to Giden et al. (2015), medication adherence refers to "the intensity of drug use during the duration of therapy, and is usually calculated by dividing the number of treatments actually taken by the patient, by number of treatments prescribed”. Despite the importance of adherence to treatment, medication non-adherence is a serious problem globally, with the World Health Organization noting that the average non-adherence rate is fifty percent among those with chronic illnesses (Haynes et al. 2002; Jin et al. 2008; Burns and Spivey 2012). Non-adherence to treatment depends on many factors, and its prevalence among those with chronic illnesses has been shown by many studies (Hashmi et al. 2007; Osamor and Owumi 2011; Kane et al. 2013). Medication non-adherence among hypertensive women has severe consequences as it leads to poorly controlled blood pressure, which increases the probability of cardiovascular (CV) problems (Khan et al. 2014).
Inadequate health literacy is one of the barriers that prevents women from adhering to hypertensive medication treatment (Persell et al. 2007; Brown and Bussell 2011; Khan et al. 2014). Health literacy is the degree to which patients can understand the basic health information needed to make appropriate health decisions. From the patient's perspective, limited health literacy might be a less-recognized barrier to medication when healthcare workers communicate with patients about their medicine regimens (Metlay et al. 2005; Tarn et al. 2006; Graham and Brookey 2008; Brown and Bussell 2011). Studies have shown that patients with limited health literacy have a poorer understanding of prescription medication names and their indications for use and instructions (Kalichman et al.1999; Wolf et al. 2005; Davis et al. 2006; Jeetu and Girish 2010). This decreased comprehension can result in poor health, reduced access to medical care and hospitalizations (Andrus and Roth 2002; Cloonan et al. 2013).

Financial constraint is another challenge for medication non-adherence among rural women with hypertension (Banerjee and Varma 2013; Ganiyu et al. 2013). Medication use and healthcare costs have increased dramatically during 
the previous decade. Adherence to medication is often a critical aspect of medical treatment, particularly the treatment of chronic conditions such as hypertension (Brown and Bussell 2011; Chisholm-Burns and Spivey 2012; Trader 2015). Another dimension of hypertension is that it affects the family of the patient because more time is needed to monitor her blood pressure. For instance, there will be numerous visits to the family doctor/clinic/hospital, as the patient's condition has to be checked several times, especially when the patient has developed certain complications. There may also be a change in the functioning of the family because the treatment regimen for hypertension is often associated with spending money which would have been allocated to family needs, to buy the patient's medication. If the family is not financially stable, the medication expenses may result in a change of the entire budget of the household (Cunningham 2008; Cohen and Kirzinger 2014).

Forgetting to take medication is also identified as a barrier that impedes medication adherence (Hong et al. 2006; Wu et al. 2008; Khatib et al. 2014). This is exacerbated by the fact that many people become forgetful as they become older (Jimmy and Jose 2011). Forgetfulness is common and is often not due to dementia. Some disorders such as depression can often cause memory problems. Certain medications can also cause confusion and memory problems in some elderly, for example, painkillers. Unexpected side effects can also sometimes cause women to discontinue or forget to take their medication. Recent findings reported by Science Daily indicated that older adults are more inclined to forget to take their medication on days when their schedule is more hectic (Brassard 2013).

Lastly, a cultural difference in relation to the non-adherence of medication treatment for hypertension is another barrier. A cultural difference refers to certain qualities of a society or a person, which are influenced by race, beliefs, tradition, language, sexual orientation, religion and nationality. According to Monane et al. (1996), the White race was significantly associated with better medication adherence as compared to the Black race and other races (Schoenthaler 2012; Brewer 2013). Research findings (Balkrishnan 1998; Forsyth et al. 2014) showed that race has an influence in medication treatment compliance. Many health beliefs and behaviors patterns are culturally based, so when two different cultures come together in a healthcare setting, a collision of expectations often occurs (Carteret 2014). Diverse healthcare providers, often view their patients' cultures as a barrier to their care. For instance, beliefs about the illness causation, especially from the patients or families that often rely on traditional healing methods, which are part of their cultural heritage, can create cultural differences that influence non-adherence to medication. The patient or family may consult a traditional healer first and only seek a Western doctor when the symptoms worsen significantly. So it is important for health and social care professionals to anticipate the communication needs around these practices. The fact that the patients' beliefs are rooted in culture, even if medication is prescribed for them, increases the chances of them skipping treatments or stopping to take their medication when their symptoms no longer show.

\section{Theoretical Framework}

The Health Belief Model (HBM) served as the theoretical framework for this study. Studies suggest that beliefs play an important role in hypertension control or management behaviors of patients (Bosworth et al. 2006; Peters et al. 2006, Wendorf et al. 2013). The Health Belief Model (HBM) is a psychological model that attempts to explain and predict health behaviors. This is done by focusing on the attitudes and beliefs of individuals. The HBM is based on the understanding that a person will take a healthrelated action (a healthy lifestyle) if that person:

- Feels that a negative health condition (that is, hypertension) can be avoided,

- Has a positive expectation that by taking recommended actions. She will avoid a negative health condition by exercising, eating healthy, having regular check-ups, medication adherence to prevent hypertension, and

- Believes that she can successfully take recommended health actions.

The model addresses an individual's perception of the threat and seriousness posed by a health problem (perceived susceptibility and severity), the perception of the usefulness of a behavior in decreasing the risk or threat of the disease (perceived benefits), and perceived barriers, which are one's perception of the obstacles to adopting the new behavior (Glanz et al. 
2008). In addition to the four main constructs, the model proposes that perceptions are modified by other variables such as age, sex, culture, education level and past experiences, which are known as modifying factors, certain events, people, and experiences that activate readiness to change, which are known as cues to action (Becker 1974). The most recent addition to the Health Belief Model is the self-efficacy construct, which allows the model to address efficacy expectations, which define the level of confidence one has in his or her ability to successfully perform specific behaviors (Bandura 1977; Rosenstock et al. 1988). Rosenstock et al. (1988) suggest that the addition of self-efficacy to the HBM offers "a more powerful approach to understanding and influencing health-related behavior than has been available to date," (p. 182). The Health Belief Model has been applied to range of health-promoting behaviors, for example, diet and exercise, to health-risk behaviors such as smoking and condom use, and to sick role behaviors, which refer to the adherence to recommended medical regimens and treatment plans (Glanz et al. 2002; Kamran et al. 2014).

\section{RESEARCH METHODOLOGY}

A qualitative exploratory research design was used to better understand the barriers of nonadherence to medication among women suffering from hypertension. A focus group data collection technique was used to explore the effect and possible causes of non-adherence. Ethical clearance was obtained from Turfloop Research and Ethics Committee (TREC) of the University of the Limpopo to conduct the study.

A purposive sampling approach was used to identify and recruit eligible participants $(\mathrm{N}=50)$ for the five (5) focus group discussions (FGD's) conducted. Each focus group discussion had an assistant moderator who took notes throughout the discussions, listened to notable quotes noting several key points in the responses to each question, monitored recording equipment, drew a diagram of the seating arrangements, and gave an oral summary and feedback after each discussion. The focus groups were guided by a semi-structured questionnaire consisting of open-ended questions, which addressed the following themes: inadequate health literacy, financial constraints, forgetting, and cultural differences.
The participants were recruited from the Dikgale Health and Demographic Health Surveillance Survey (HDSS), a site that is located in the Central Region, Capricorn District, of Limpopo Province, in South Africa. It is approximately 40 kilometers from Polokwane, the capital city of the Limpopo Province and 15 kilometers away from the University of Limpopo. The participants had to meet several criteria to be considered for the study. Firstly, only Black women were selected. Secondly, only group members who were above 18 years of age were considered for the study. Lastly, they had to have been diagnosed with hypertension. The NVivo program was used to manage and organize the qualitative data. The results were presented in a thematic analysis. The analysis involved identifying, examining and recording patterns (or "themes") within the data.

The aim of this study was to explore the barriers to non-adherence among hypertensive women living in rural areas. The specific objective of this study was to determine and assess the extent and reasons for non-adherence among women suffering from hypertension.

\section{RESULTS}

Presentation of the results and subsequent discussions are based on four themes. These include inadequate health literacy, financial constraints, forgetting and cultural differences. The researchers illustrate the results with quotations from the participating women, labeling them with the name of the residence in which the FGD's were conducted.

\section{Inadequate Health Literacy}

The participants talked about their understanding of their condition, how they sometimes try to manage it and how they engage with health information and health services. The challenge is that some of them are illiterate, and they cannot read/ write properly, and as a result they find it difficult to understand the healthcare practitioners' prescriptions and instructions. One participant said:

"I did not go to school; it is very hard to follow the doctor's instructions of drinking my medication, unless when I requested my grandson to accompany me to the clinic, so that the doctor explains to him, the next date of the 
appointment, how many pills should I take and what time..." (FGD Nchichane)

From the participants' perspective, communication with health and social care providers is often insufficient and may contribute to medication non-adherence. Ineffective communication between the health and social care providers and the patient with hypertension further compromises the patient's understanding of the disease, its potential complications, and the importance of medication adherence. The following quote illustrate the point expressed:

"Go bolelannete, gaketsebe kudu kabolwetsibjaka, se ketsebagoke gore kena le 'madi a magolo.' Gantsi rena ka Sesotho re a lomega gore re kaonafale. Go ka re ma Nurse baka re hlalosetsakotsiya go se lateleditaelotsa go nwadipilisikamehla”

Literally meaning:

"To be honest, I do not know much about my disease, what I know is that I have 'high blood pressure'. In most cases we practice bloodletting (Bloodletting is the withdrawal of often small quantities of blood from a patient to cure or prevent illness and disease). I wish the nurses can share with us the danger of not adhering to medication all the time."(FGD Muduwane)

Failing to elicit a history of alternative, herbal, or supplemental remedies/treatments from the participants was raised as another source of ineffective communication.

"Ge batsaleago le batsamaphelogebabebakanyakisisa gore kantle le dihlaretsetsasegowa, re thuswakeeng? Ke bolela se, ka gore ba bantsi ba rena, re sa dumela mo go se Afrika, re a di hlakantsa dihlare tse."

Literally meaning:

"If social and healthcare workers can do research to explore the reasons for us not to rely on Western medication, what else can assist us? I am saying this because we still believe in an African culture and still mix traditional herbs and the western medication." (FGD Sefateng)

Not only do physicians often fail to recognize medication non-adherence in their patients, they may also contribute to it by prescribing complex drug regimens, failing to explain the benefits and adverse effects of a medication effectively and failing to consider the financial burden of the drug regimen on the patient.

\section{Financial Constraints}

The participants indicated that hypertension is a condition that needs regular check-ups, and that this involves money for transport. When she is unable to visit her physician, the patient will fail to get her medication on time, and as a result the patient will develop complications because she does not have medication. The following quotation illustrates this problem:

"I used to miss the doctor's appointment due to lack of money for transport to go to the clinic, by then my pills were finished, and there was no one to send to the clinic for my medication. Some of the women I know, who suffer from hypertension do walk to the clinic, even though it is miles away. As you can see me, my feet are painful and the issue of being overweight..." (Laughing). (FGD Madiga)

In collaboration of what was said, another participant stated:

"I wish the government could assist with a mobile clinic, so that those who fail to reach the clinic due to understandable reasons can be helped. It is difficult because you find that the illness becomes worse if one has missed her medication." (FGD Sebateng)

The participants highlighted another challenge related to adhering to medication, which is that sometimes the clinics do not have the hypertension drugs (which are dispensed to the patients free of charge). This poses a challenge, as patients do not have money to buy the drugs from a chemist or pharmacy. As a result of this, their basic needs are not met, since the patients will sometimes opt to buy medication instead of food. The majority of the participants in the study were unemployed and relied on social grants and piece jobs such as domestic work. The following excerpts illustrate some of the participants' views on this issue:

"...Because of not getting medication from the clinic, the small amount of money we have is spent on medication and we are left without food."(FGD Solomondale).

"It depends on how many diseases do you have. I said I have arthritis, hypertension and ulcers. I can spend about R500 on that medication, and in most instances I do not buy all medication, I just buy some I know I do not have. So you tell me, from the R1000 I have and I spend R500, how much am I left with? How 
will I survive? I have to buy electricity and food. I am suffering." (FGD Solomondale)

"If you are using Adalat 50, it costs R400, Adalat 30 is R270... You do not buy medication for one disease; every disease has its own medication. Then you don't have money to buy for all of those diseases." (FGD Nchichane)

"Our financial budget is affected. We are concerned. You find that I did not plan to buy medication. You will be obliged to take the remaining money to buy life. We are struggling." (FGD Muduwane)

\section{Forgetting}

The majority of the participants in this study were elderly. Most of the participants identified forgetting as a crucial barrier to medication adherence. The participants seemed to be willing to follow their medication regimen, however, sometimes they just "forgot".

"I mostly forget to take my medication and I believe that forgetting is often associated with poor organization and getting old. "(FGD Madiga)

Another reason raised by the participants that causes them to forget to take their medication is lack of family support that is not having someone to remind them to take their medication. While forgetfulness on the part of the participants is also a factor, the researchers see it as unintentional non-compliance. Regardless of memory loss or forgetfulness, the fact remains that if the participants do not take their medication, it is not beneficial to them.

\section{Cultural Differences}

All the participants were Black African females. They explained their cultural beliefs with regards to hypertension, especially the belief that one of the causes of hypertension is heredity.

"My mother and grandmother suffered from hypertension. It is hereditary. In the past, the illness was not noticeable because our parents would in the absence of other treatments for hypertension, do bloodletting to draw blood." (FGD Muduwane)

"We had a male paternal relative who was a traditional healer. My traditional mother took me to the healer. When we arrived, they perform their usual way of throwing the bones in order to find out what could be my problem. He told my mother that I was not bewitched but suffered from ngope (hypertension). The traditional healer took few small wooden sticks and told my mother that when she arrives home, she must cook on the fire place, burn wood, put on the traditional bowl called "lengata" and put the sticks inside, and take a blanket, cover me (for the sticks to burn so to inhale the smoke). When the smoke was too strong for me to handle, I would scream and say mama I am dying. " (FGD Muduwane)

It was discovered that the majority of the participants consult traditional healers. The participants also indicated that they still adhere to the cultural norms and expectations of their traditions and that most of their chronic illnesses need the traditional healer's intervention first. They seek Western medical attention when the symptoms get worse.

"When we attempt to understand the illness or disease, we will ask the questions why and who. My belief is that any mental and physical illnesses can be caused by failure to perform traditional rituals..." (FGD Muduwane)

"I mix (both traditional and Western medicine) because I want to preserve my culture... So under those circumstances I am obliged to go to the clinic and traditional healers." (FGD Sefateng)

"The use of traditional medicine is highly recommended in my family. For hypertension the 'ngaka' traditional healer uses a mixture of herbs and other secret stuff, but the most common administration method is boiling a root and drinking the decoction." (FGD Nchichane)

\section{DISCUSSION}

The participants in the study provided a variety of vivid explanations for their reasons for not adhering to their medication regimes. Women living with hypertension were selected to participate in this study since hypertension is the most common chronic condition in South Africa (Hasumi and Jacobsen 2012; Health24 2013; The Heart and Stroke Foundation-South Africa 2013; MEDIMED 2013).

Patients with health literacy problems are less likely to understand and participate in disease prevention and health promotion programs (Gazmararian et al. 1999; Scott el al. 2002; Adams 2010) and are more likely to be hospitalized, than those with adequate health literacy (Baker 2002; Dennison 2011). From this study, it seems that 
the problem of inadequate literacy is greater in older patients. Findings from previous research conducted show that the majority of patients older than 60 years of age perform at the lowest levels of literacy, and have limited ability to fill out forms (National Center for Education Statistics 2005; Duhaney 2010). According to the participants, at times the medical condition is not explained to them in words they can understand with the assumption that patients can read and understand the materials given to them. This shows that inadequate health literacy can result in difficulty in accessing healthcare, following instructions from a doctor, and taking medication properly (Safeer and Keenan 2005; Oladunjoye 2013). Medical information is communicated better when spoken slowly (Safeer and Keenan 2005), when simple words are used and a restricted amount of information is presented.

Determinants to therapeutic non-adherence to medicine have been studied extensively in the past, especially in Western countries such as Europe and the US (Vermeire et al. 2002; Kardas et al. 2013). The predictors for non-adherence to medicine remain complex and dependent on personal and contextual factors. This study has presented a unique insight into the opinions and beliefs of the patients themselves, within their personal and culturally specific context. The two main determinants that can be derived from the results are medication cost and cultural barriers.

With regards to financial constraints, medication costs pose a significant burden to many adults with hypertension and therefore contribute to decreased treatment adherence. Many participants reported cutting back on basic needs to pay for their medication, and many others incurred debt or borrowed money from family members and friends to pay for their medication. These financial consequences of the cost of medication affect the health and well-being of women with hypertension. The Dikgale communities experience a high rate of unemployment and poverty hence the majority of the participants in this study are elderly and are taking care of their children and grandchildren who are unemployed. Due to their advanced age, most of the participants identified forgetfulness as a crucial barrier to their medication adherence. Forgetfulness has been well documented in other studies as the most common reason for medica- tion non-adherence (Hong et al. 2006; Jimmy and Jose 2011; Khatib et al. 2014).

Cultural barriers to treatment and compliance are not always easy to ascertain, and therefore create gaps in effective communication, that impedes the success of treatment. There is no way for health and social care professionals to predict specific cultural barriers with certainty in every situation, so cross-cultural communication skills become extremely important in uncovering misperceptions that will impede treatment (Carteret 2014). In the specific rural South African context, it seems crucial to take on board the people who perform traditional healing rituals as partners in healthcare. The study has shown that the majority of women's beliefs lie in traditional rituals and practices to remain in and to regain good health. Although traditional healing rituals have gained only limited acknowledgement from the mainstream medicine community, they can serve as a means to detect health problems in their early stages in the Black African community. The results have shown that women suffering from hypertension tend to seek help from traditional healers in the early stages of health problems. It is only in the later stages that they turn to Western medicine.

\section{CONCLUSION}

Women with inadequate health literacy face many obstacles when accessing and using the healthcare system. Literacy problems can inhibit a woman's ability to attend appointments or follow the doctor's instruction on how to take her medication. Financial constraints pose a serious challenge to many women living with hypertension, since they have to compromise their health and family when they opt to buy medication instead of other basic needs. Forgetfulness is seen as an unintentional non-compliance. The participants still adhere to their cultural norms and expectations. This is a challenge that the health and social care providers can explore in the pursuit for better health for their patients, and to raise awareness to their patients about the danger of not adhering to medication.

The researchers believe these results can further help healthcare workers understand the way people cope with medication use and furthermore, the results give more insight for healthcare workers to improve treatment for chronic patients in the rural area of Dikgale. An impor- 
tant aspect in the improvement of treatment for chronic patients is the involvement of traditional healers as key figures in the community to detect health problems in their early stages. Therefore the role of traditional healers in primary healthcare should not be underestimated.

\section{RECOMMENDATIONS}

Health and social care professionals should be aware that most patients are unwilling to admit that they have literacy problems, financial constraints, are forgetful and have cultural differences. The medication instructions should comprise short words, simple sentences, and have clear illustrations. In addition, health and social care professionals should verbally reinforce written instructions. Complementing each other at professional level, social service professionals, through assessment can assist if clients are referred to them by the healthcare practitioners, by referring the patients to appropriate and relevant resources for further intervention. Furthermore, these professionals can assist the elderly in dealing with their forgetfulness through patient education sessions and home visits, when considering that chronic forgetfulness is most often associated with poor organization and cognitive decline.

To maximize understanding in the context of cultural differences, health and social care professionals need to build up rapport with patients in order to demonstrate an awareness of culturally based family dynamics, recognize how different cultures perceive medical assistance and how this perception affects open communication. The health and social care professionals can also express an awareness of traditional remedies used by many patients from various cultures, as well as take a genuine interest in the patients' use of these remedies and cures without judgment.

\section{REFERENCES}

Adams JR 2010. Improving health outcomes with better patient understanding and education. Risk Manag Healthcare Policy, 3: 61-72.

Alberts M, Burger S 2002. Dikgale DSS, South Africa. In Population and Health in Developing Countries, Vol.1, Population, Health, and Survival in INDEPTH Sites, 1: 207-211. Canada: International Development Research Centre. From <http://www.cdc.gov/ features/africanamericanhistory/> (Retrieved on 12 February 2014).
Andrus MR, Roth MT 2002. Health literacy: A review. Pharmacotherapy, 22(3): 282-302.

Baker DW, Gazmararian JA, Williams MV, Scott T, Parker RM, Green D 2002. Functional health literacy and the risk of hospital admission among Medicare managed care enrollees. Am J Pub Health, 92: 1278-1283.

Balakrishnan JD 1998a. Measures and interpretations of vigilance performance: Evidence against the detection criterion. Hum Factors, 40: 601-623.

Bandura A 1977. Self-efficacy: Toward a unifying theory of behavioral change. Psychological Review, 84(2): 191-215.

Banerjee S, Varma R 2013. Factors Affecting NonAdherence among Patients Diagnosed with Unipolar Depression in a Psychiatric Department of a Tertiary Hospital in Kolkata, India. Depression Research and Treatment 2013, 12 pages.

Becker M 1974. The health belief model and personal health behavior. Health Educ Monogr, 2(4): 324353.

Bosworth HB, Dudley T, Olsen MK, Voils CI, Powers B, Goldstein MK, Oddone EZ 2006. Racial differences in blood pressure control: Potential explanatory factors. Am J Med, 119(1): 9-15.

Brassard S 2013. About the Elderly Forgetting to take Medications. From <http://www.livestrong.com/article/206756-about-the-elderly-forgetting-to-takemedications/> (Retrieved on 1 August 2014).

Brewer LC, Carson KA, Williams DR, Allen A, Jones CP, Cooper LA 2013. Association of race consciousness with the patient-physician relationship, medication adherence, and blood pressure in urban primary care patients. Am J Hypertens, 26(11): 13461352.

Brown MT, Bussell KJ 2011. Medication adherence: WHO cares? Mayo Clin Proc, 86(4): 304-314.

Burns MA, Spivey CA 2012. The 'cost' of medication non-adherence: Consequences we cannot afford to accept. J Am Pharm Assoc, 52(6): 823-826.

Carteret M 2014. Cross Cultural Consideration in Prescribing Medication. From <http://www. dimensionsofculture .com/2014/03/cross-cultural-considerations-in-prescribing-medication/> (Retrieved on 15 July 2014).

Chisholm-Burns MA, Spivey CA, Sredzinski E, Butler SL 2003, 2012. Intervention toolbox to promote immunosuppressant therapy adherence in adult renal transplant recipients. J Am Pharm Assoc, 52(6): 816-822.

Cloonan P, Jade W, Joan R 2013. Reducing 30-day readmissions: Health literacy strategies. J Nurs Adm, 43(7/8): 382-387.

Davis TC, Wolf MS, Bass PF, Tilson H, Neuberger M, Parker RM 2006. Literacy and misunderstanding of prescription drug labels. Ann Intern Med, 145: 887894.

Dennison CR, McEntee ML, Samuel L, Johnson BJ, Rotman S, Kielty A, Russell SD 2011. Adequate health literacy is associated with higher heart failure knowledge and self-care confidence in hospitalized patients. J Cardiovasc Nurs, 26(5): 359-367.

Donovan JL, Blake DR 1992. Patient non-compliance: Deviance or reasoned decision-making? Soc Sci Med, 34(5): 507-513.

Dowse R, Ehlers MS 2003. The influence of education on the interpretation of pharmaceutical pictograms for communicating medicine instructions. Int $J$ PharmPract, 11: 11-18. 
Duhaney MC 2010. Raising awareness on the health literacy epidemic. In: RA Norman (Ed.): Preventative Dermatology. Chapter 3. London: Springer-Verlag, pp. 21-33.

Forsyth J, Schoenthaler A, Chaplin WF, Ogedegbe G, Ravenell J 2014. Perceived discrimination and medication adherence in black hypertensive patients: The role of stress and depression. Psychosom Med, 76(3): 229-236.

Ganiyu AB, Mabuza LH, Malete NH, Govender I, Ogunbanjo GA 2013. Non-adherence to diet and exercise recommendations amongst patients with type 2 diabetes mellitus attending Extension II Clinic in Botswana. Afr J Prm Health Care Fam Med, 5(1): Art. \#457, 6 pages.

Gazmararian JA, Parker RM, Baker DW 1999. Reading skills and family planning knowledge and practices in a low-income managed-care population. Obst Gyn, 93: 239-244.

Glanz K, Rimer B, Lewis F 2002. Health Behavior and Health Education: Theory, Research, and Practice. $3^{\text {rd }}$ Edition. San Francisco, CA: Jossey-Bass, pp. 97122.

Glanz K, Rimer BK, Viswanath K 2008. Health Behavior and Health Education: Theory, Research, and Practice. $4^{\text {th }}$ Edition. San Francisco, CA: JosseyBass, pp. 45-51.

Graham S, Brookey J 2008. Do patients understand? Perm J, 12(3): 67-69.

Hashmi SK, Afridi MB, Abbas K, Sajwani, RA, Saleheen D, Frossard PM 2007. Factors associated with adherence to anti-hypertensive treatment in Pakistan. PLoS One 2(3): e280.

Hasumi T, Jacobsen KH 2012. Hypertension in South African adults: Results of a nationwide survey. $J$ Hypertens, 30(11): 2098-2104.

Haynes RB, McDonald H, Garg AX, Montagne P 2002. Interventions for helping patients to follow prescriptions for medication. JAMA, 11, 288(22): 28682879.

Hong TB, Oddone EZ, Dudley TK, Bosworth HB 2006. Medication barrier and anti-hypertensive medication adherence: The moderating role of locus of control. Psychol Health Med, 11(1): 20-28.

Jeetu G, Girish T 2010. Prescription drug labeling medication errors: A big deal for pharmacists. J Young Pharm, 2(1): 107-111.

Jimmy B, Jose J 2011. Patient medication adherence: Measures in daily practice. Oman Med J, 26(3): 155-159.

Jin J, Sklar GE, Min Sen Oh V, Chuen Li S 2008. Factors affecting therapeutic compliance: A review from the patient's perspective. Ther Clin Risk Manag, 4(1): 269-286.

Kalichman SC, Ramachandran B, Catz S 1999. Adherence to combination antiretroviral therapies in HIV patients of low health literacy. J Gen Intern Med, 14: 267-273.

Kamran A, Ahari SS, Biria M, Malepour A, Heydari H 2014. Determinants of patient's adherence to hypertension medications: Application of health belief model among rural patients. Ann Med Health Sci Res, 4(6): 922-927.

Kane JM, Kishimoto T, Correll CU 2013. Non-adherence to medication in patients with psychotic dis- orders: Epidemiology, contributing factors and management strategies. World Psychiatry 12(3): 216226.

Kardas P, Lewek P, Matyjaszkzyk M 2013. Determinants of patient adherence: A review of systematic reviews. Front Pharmacol, 4(91): 1-16.

Khan MU, Shah S, Hameed T 2014. Barriers to and determinants of medication adherence among hypertensive patients attended National Health Service Hospital, Sunderland. J Pharm Bioallied Sci, 6(2): 104-108.

Khatib R, Schwalm J-D, Yusuf S, Haynes RB, McKee M 2014. Patient and healthcare provider barriers to hypertension awareness, treatment and follow up: A systematic review and meta-analysis of qualitative and quantitative studies. PLoS ONE, 9(1): e84238.

Khatib R, Schwalm J-D, Yusuf S, Haynes RB, McKee M, Khan M, Nieuwlaat R 2014. Patient and healthcare provider barriers to hypertension awareness, treatment and follow up: A systematic review and meta-analysis of qualitative and quantitative studies. PLoS ONE 9(1): e84238.

Krousel-Wood MA, Frohlich ED 2010. Hypertension and depression: Co-existing barriers to medication adherence. J Clin Hypertens (Greenwich), 12(7): 481-486.

Metlay JP, Cohen A, Polsky D, Kimmel SE, Koppel R, Hennessy S 2005. Medication safety in older adults: Home-based practice patterns. J Am Geriatr Soc, 53: 976-982.

Livestrong Organisation 2015. About the Elderly Forgetting to Take Medication. From < http://www. livestrong.com/article/206756-about-the-elderlyforgetting-to-take-medications/> (Retrieved on 8 November 2015).

Mayoclinic 2015. Reversible Causes of Memory Loss. From <http://www.mayoclinic.org/diseases-conditions/alzheimers-disease/in-depth/memory-loss/art20046326?pg=2> (Retrieved on 8 November 2015).

Monane M, Bohn RL, Gurwitz JH, Glynn RJ, Levin R, Avorn J 1996. Compliance with antihypertensive therapy among elderly Medicaid enrollees: The roles of age, gender, and race. Am J Public Health, 86(12): 1805-1808.

Mosack KE, Patterson L, Brouwer MA, Wendorf AR, Ertl K Eastwood D, Morzinski J, Fletcher K, Whittle J 2013. Evaluation of a peer-led hypertension intervention for veterans: Impact on peer leaders. Health Educ Res, 28(3): 426-436.

National Center for Education Statistics, US Department of Education 1996. Literacy of Older Adults in America. Washington, D.C.: From <http://nces. ed.gov/pubs97/97576.pdf.> (Retrieved 10 November 2015). In: SR Safeer, J Keenan (Eds.): Health Literacy: The Gap Between Physicians and Patients. Am Fam Physician, 72(3): 463-468.

Oladunjoye AO, Adebiyi AO, Cadmus EO, Ige OK, Oladunjoye OO 2013. Health literacy amongst tuberculosis patient in a general hospital in North Central Nigeria. J Comm Med Prim Healthc, 24(1 and 2): 44-49.

Osamor PE, Owumi BE 2010. Complementary and alternative medicine in the management of hypertension in an urban Nigerian community. BMC Compl Alternative Med, 10: 36.

Persell CD, Osborn CY, Richard R, Skripkauskas S, Wolf MS 2007. Limited health literacy is a barrier to 
medication reconciliation in ambulatory care. J Gen Intern Med, 22(11): 1523-1526.

Peters E, Lipkus I, Diefenbach MA 2006. The functions of affect in health communications and in the construction of health preferences. J Commun, 56: S140-S162.

Sachdeva S 2005. The tricky nature of medication compliance. Review by Osterberg L, Blaschke T. Adherence to Medication. $N$ Engl J Med, 353: 487-497.

Safeer SR, Keenan J 2005. Health literacy: The gap between physicians and patients. Am Fam Physician, 72(3): 463-468.

Schoenthaler A, Allegrante JP, Chaplin W Ogedegbe 2012. The effect of patient-provider communication on medication adherence in hypertensive black patients: Does race concordance matter? Ann Behav Med, 43(3): 372-382.

Scott JM, Heglund PJ, Samson F, Haufler J, Morrison M, Raphael M, Wall B 2002. Predicting Species Occurrences: Issues of Accuracy and Scale. Covelo, California: Island Press, P. 868.

Tarn DM, Heritage J, Paterniti DA, Hays RD, Kravitz RL, Wenger NS 2006. Physician communication when prescribing new medications. Arch Intern Med, 166: $1855-1862$

Trader J 2015. Medication Non-adherence: Healthcare's Avoidable Achilles Heel. From <http://www.r ightpatient.com/blog/medication-nonadherencehealthcares-avoidable-achilles-heel/> (Retrieved on 4 November 2015).

Vermeire K, Zhang Y, Princen K, Hatse S, Samala MF, Dey K, Choi HJ, Ahn Y, Sodoma A, Snoeck R 2002. CADA inhibits human immunodeficiency virus and human herpesvirus 7 replication by down-modulation of the cellular CD4 receptor. Virology, 302: 342-353.

Wolf MS, Davis TC, Arozullah A, Penn R, Arnold C, Bennett CL 2005. Relationship between literacy and HIV treatment knowledge among individuals enrolled in HAART regimens. AIDS Care, 17: 863-873.

Wu J-R, Moser DK, Lennie TA, Chung ML, DeJong MJ 2008. Medication adherence mediates the relationship between ethnicity and event-free survival in patients with heart failure. J Card Fail, 14: S95.

Paper received for publication on October 2014

Paper accepted for publication on November 2015 